\title{
Determinants of precancerous cervical lesion among women screened for cervical cancer in south Ethiopia: A case-control study
}

Tesfalidet Tekelab Beyene ( $\nabla$ ttesfalove@gmail.com )

Wollega University https://orcid.org/0000-0003-0774-7708

Mohammed Akibu

Debre Berhan University

Henok Bekele

Pharma college

Wengelawit Seyoum

Pharma college

Research article

Keywords: Precancerous lesions, cervical cancer, Ethiopia

Posted Date: September 25th, 2019

DOI: https://doi.org/10.21203/rs.2.14781/v1

License: (9) This work is licensed under a Creative Commons Attribution 4.0 International License.

Read Full License 


\section{Abstract}

Background Nearly $90 \%$ of deaths from cervical cancer occurred in low resource setting. In Ethiopia the magnitude of cervical cancer was $17 \%$. Precancerous cervical lesions may progress to cervical cancer. Early screening and treatment of precancerous cervical lesions is a cost effective way to avert the growth of cervical cancer. However, there is a limited research on risk factors of precancerous cervical lesions in Ethiopia. Therefore the aim of this study was to identify determinants of precancerous cervical lesions in south Ethiopia.

Method A facility based case-control study was carried out in five health facilities in south Ethiopia between 8 May to 28 September 2018. Interviewer administered questionnaires were used to collect data from 98 cases and 197 controls. Multivariate logistic regression was employed to identify determinants of precancerous cervical lesions.

Results Women aged 30-39 years (AOR $=2.51,95 \% \mathrm{Cl}: 1.03-6.08)$, monthly income $<42$ USD and 43-66 USD (AOR $=3.41,95 \% \mathrm{Cl}: 1.34-6.08 ; \mathrm{AOR}=3.63,95 \% \mathrm{Cl}: 1.31-9.88)$, initiation of first sexual intercourse at age less than or equal to $20(\mathrm{AOR}=2.39,95 \% \mathrm{Cl}: 1.14-5.47)$, having more than one life time sexual partners (AOR=4.70,95\% Cl:2.02-10.95), having a partner/ husband with more than one lifetime sexual partners (AOR=2.98, 95\% Cl: 1.35-6.65) had higher odds of precancerous cervical lesions.

Conclusion Strategies to prevent precancerous cervical lesions should focus on modification of life style and sexual behaviour. The findings of this study highlight implications for policy makers by suggesting that targeting older women for cervical cancer screening, addressing inequalities and education relating to risky sexual behaviour may reduce precancerous cervical lesions. Further longitudinal study is needed to assess awareness of women about cervical cancer screening.

\section{Introduction}

Worldwide, Human papillomavirus (HPV) are the utmost prevalent human viral infections that can infect the skin and mucous membranes. HPV are transmitted via skin-to-skin and sexual contact $(1,2)$. HPV is one of the most common causes of cervical cancer and the precursor lesions(3). Cervical cancer is the fourth utmost cancer in women with an estimated 530,000 new cases worldwide in 2018, resulting $6.6 \%$ of all women cancers(4). Every minute of every day, a new case of cervical cancer affects a woman (5). According to the 2018 World Health Organization(WHO) report; ninety percent of deaths from cervical cancer occurred in low resource setting(4). Sub-Saharan Africa has the utmost burden of cervical HPV infection such as in Mozambique $(41 \%)$ and Guinea $(48 \%)(5,6)$. In low resource settings, detection of precancerous cervical lesion may be accomplished using Visual inspection of the cervix using acetic acid (VIA). Cervical cancer screening with VIA is simple and affordable and can be combined with simple treatment for early cervical lesions(7). 
In Ethiopia, cervical cancer ranks as the second leading cause of female cancer after breast cancer in women aged 15 to 44 years. In 2012, there were 7,095 new cases of cervical cancer and 4,732 mortality. In Ethiopia, the magnitude of cervical cancer was $17 \%$ and a mortality of $16.5 \%(8)$. The national health sector development program IV, developed in 2010, which contains the prevention and control and screening of cervical cancer (9). Following this program federal Ministry of Health has recently planned and developed a nationwide standard on screening, prevention and control for cervical cancer(10). Currently, in Ethiopia cervical cancer screening centres have begun to provide cervical screening services(10). However, awareness, uptake and acceptance of cervical cancer screening is low (11-14).

The literature has reported risk factors that has been linked to cervical cancer and its precursors $(15,16)$. The risk for developing cervical cancer is associated with multiple sexual partners, sexually transmitted infection and early age of first intercourse $(15,17$, 18). There are a limited research in Ethiopia on risk factors of precancerous cervical lesion $(15,19)$. Most of the research done in Ethiopia focused on awareness, prevalence, determinants of cervical cancer screening and risk factors of cervical cancer in HIV positive women(11, 12, 19, 20). To the best of our knowledge this is the first study to identify determinants of precancerous cervical lesions in south Ethiopia. The findings of this study will be an input for policy makers in order to prevent precancerous cervical lesions that result in cervical cancer. In addition, it helps health providers to identify the most common risk factors that increase the likelihood of cervical cancer in the study area. Therefore, we aimed to conduct a study to address determinants of precancerous cervical lesions in south Ethiopia.

\section{Methods}

\section{Study setting and study participants}

This was a case-control study involving women aged 21-49 years who had undergone screening for precancerous cervical lesion by VIA. The study was conducted between 8 May to 28 September 2018 at five selected health facilities in Southern Nations, Nationalities and Peoples' Region (south Ethiopia), Ethiopia. The capital city of the region is Hawassa, which is $285 \mathrm{~km}$ from Addis Ababa. According to the Central Statistical Agency of Ethiopia (CSA) report, south Ethiopia has a total population of 15 million, of whom $50.3 \%$ are women. The selected health facilities were Hawassa University Comprehensive Specialized Hospital, Durame General Hospital, Arba Minch general Hospital, Adare Hospital and Yirgalem Hospital.

The study participants were identified from those screened by VIA. Cases were all age eligible (21 - 49 years) women who have been screened for cervical cancer and tested 
positive for VIA (women with suspected precancerous lesion) with available testing methods and controls were all age eligible (21 - 49 years) women who presented to the same health facility for cervical cancer screening but free of suspected precancerous lesion.

\section{Sample size}

The sample size was calculated with Open Epi version 3 statistical software. Assuming proportion of controls (women without precancerous cervical lesion) with life time number of sexual partner two and above (30.57\%), odds ratio $2.17(15)$, power $80 \%$, 95\% confidence interval, non-response rate $10 \%$ and ratio of cases to control $1: 2$, our final sample size was 300(100 cases and 200 controls).

\section{Data collection tool and technique}

Data was collected using an interviewer administered questionnaire which was developed after reviewing various similar literatures (15-19). The questionnaire encompassed sociodemographic characteristics, reproductive characteristics, lifestyle and sexual behaviours. The questionnaires were developed in English, translated into regional language (Amharic). To maintain the consistency, the questionnaire retranslated back to English by people who are proficient in both languages. The interview was conducted in private room to create confidence within a secure environment.

\section{Data quality assurance}

A pertest was performed to check the consistency of the tools. Data was collected by five experienced midwives from each health facility. Training was given for one day in relation to the objective, significance of the study, confidentiality of information, respecting the rights of the participants and informed consent. Five supervisors recruited to oversee the data collection process. All the data was checked for clarity, completeness and consistency by data collectors, supervisors and the principal investigator.

\section{Data management and analysis}

Data analysis was carried out by SPSS version 20. Data were cleaned by running frequency, cross tabulation and summary statistics. Both bivariate and multivariate logistic regression analyses were carried out to identify determinants of precancerous cervical lesions. Bivariate analysis was executed between the dependent variable and each of the 
independent variables. Variables with a p-value less than 0.2 in the bivariate analyses were included in multivariable models. To avoid residual confounding in multivariate analysis, a p-value less than 0.20 was considered adequate(21). Multivariable logistic regression using an adjusted odds ratio (AOR) was carried out to identify the independent determinant of precancerous cervical lesions.

\section{Results}

A total of 98 cases and 197 controls were recruited which give the response rate of $98.7 \%$. The mean and standard deviation of the participant age were $32.7 \pm 5$.3. More than two thirds (67.3\%) of cases and more than half (59.9\%) of controls were in the age group of 3039 years. Fifty four (55.1\%) cases and 120 (60.9\%) controls came from urban residence. Forty four (44.9\%) of cases and more than half (55.8) controls reported being followers of a protestant religion. The majority (91.8\%) of cases and the majority (90.4\%) of controls were married. More than one quarter (26.5\%) of cases and $45(22.8 \%)$ of controls had primary (grade 5-8) as their highest educational level. By occupation, one third of both cases and controls were housewives. Thirty nine (39.8\%) of cases and 48(24.4\%) of controls had a monthly income less than 43 USD (Table1).

\section{Reproductive Characteristics}

Fifty nine (60.2\%) of cases and the majority (90.9\%) of controls have one to four children. The mean and standard deviation of age at menarche of the participants were 15.2 \pm 1.7 . More than two third (68.4\%) of cases and nearly three quarter $(72.1 \%)$ of controls reported having a regular menstrual history. Half (51.0\%) of cases and nearly half (46.7\%) of controls reported currently using contraceptive. Nearly half of the cases and controls currently reported using injectable contraceptive. More than half of cases and controls ever used oral contraceptive methods. The birth interval was similar between cases and controls, $70.2 \%$ and $70.1 \%$ gave birth after two years. The majority of cases $(93.9 \%)$ and controls (94.4\%) had no history of recurrent abortion. More than half (53.1\%) of cases and nearly half (48.7\%) controls had their first pregnancy at the age of less than 21 years (Table2).

\section{Life style and sexual behaviours}

Eighty four (85.7\%) of cases and 149 (75.6\%) of controls reported first sexual intercourse after the age of 20 years. One third (33.7\%) of cases and 16 (8.1\%) reported having multiple sexual partners. Thirty six (36.7\%) of cases and $37(18.8 \%)$ of controls reported that their husbands or partners had two or more sexual partners. The majority of cases and controls reported no history of sexually transmitted diseases (STD). Seventeen (17.3\%) of cases and 17 (8.6\%) controls reported that their husband or partner had a history of STD. 
Most of cases and controls reported no family history of cervical cancer. Nearly one sixth of the cases reported a history of post-coital bleeding. Twenty one $(21.4 \%)$ of cases reported having ever been screened for cervical cancer. The prevalence of HIV is higher (13.3\%) in the cases than controls. The majority of cases and controls reported no history of smoking. Nearly three quarters $(73.5 \%)$ of cases reported that they wash their vulva after sexual intercourse (Table3).

Those respondents in the age of 30-39 years had a higher likelihood of a precancerous cervical lesion compared to those who were in the age group 21-29 and 40-49 years(AOR = 2.51, 95\% CI: 1.03 - 6.08). Respondents having monthly household income $\leq 42$ USD and 43-66 USD were three times more likely to develop a precancerous cervical lesion than those whose monthly household income was more than 67 USD (AOR $=3.41,95 \%$ CI: 1.34 - 6.08; AOR = 3.63, 95\% CI: 1.31 - 9.88). Respondents who started their first sexual intercourse at age less than or equal to 20 years were two times more likely to have a precancerous cervical lesion (AOR $=2.39,95 \%$ CI: $1.14-5.47$ ). Respondents who had two or more life time sexual partners were nearly five times more likely to have precancerous cervical lesion( AOR=4.70, CI :2.02-10.95). Similarly having a partner or husband with two or more other lifetime sexual partners was associated with having a precancerous cervical lesion (AOR=2.98 CI: 1.35-6.65) (Table4)

\section{Discussion}

Cancer is progressively a major public health burden in both high income and low income countries(22). Globally, the high mortality rate from cervical cancer could be reduced through a comprehensive approach such as identifying the risk factors, prevention and early detection, effective screening and treatment programmes(23). Identifying the risk factors of precancerous cervical lesions is important to policy makers to develop strategies in prevention of cervical cancer. Thus the aim of this study was to identify the determinants of precancerous cervical lesion in south Ethiopia.

Studies indicated that older women had higher likelihoods of having precancerous cervical lesion than younger women $(15,24)$. The present study showed that respondents who were aged 30-39 years were more likely to have precancerous cervical lesion compared to others. A study done on age specific incidence of cervical cancer found that cervical cancer increases rapidly with age and usually reached peak at age 40 years (25). However, there are studies done elsewhere in Ethiopia which reported age had no association with precancerous cervical lesions $(19,26)$. The difference may be due to difference in study participants; the present study included women who were in their reproductive age groups but the latter studies include only HIV positive women. 
Evidence from low and middle income countries has shown that low individual socioeconomic status influences health outcomes through a lack of awareness about the health impact of lifestyle risk factors and reduced access to healthcare for financial reasons (2729). Our study showed that women who reported monthly household income less than or equal to 66 USD were more likely to have a precancerous cervical lesion compared to those who reported an income of more than 66 USD. A meta-analysis done on risk of cervical cancer indicated that the risk of having cervical cancer is highest among women who had low income $(30,31)$. The possible explanation for this may be that women with low income may not get accesses to health care service because of financial hardship. Furthermore, financial hardship may influence the health of the women by limiting access to information about the health impact of lifestyle risk factors or access to routine screening. This study alludes the importance of reducing inequalities to prevent and enable early detection of precancerous cervical lesions.

Our analysis showed that early initiation of sexual intercourse increase the risk of precancerous cervical lesion which is consistent with studies done elsewhere and in the country $(16-18,32,33)$. The association between early first sexual intercourse and cervical cancer can be explained by the fact that during adolescence cervical tissue undergoes biological changes, which has been recognized as the site in which human papilloma virus infection tends to cause cancer. Moreover, physiological immaturity during adolescence has been identified as a predisposing factor for precancerous cervical lesion $(34,35)$. Our finding was inconsistent compared to study done in Addis Ababa which indicated that early sexual intercourse was not associated with precancerous cervical lesion (15).The reason for this difference might be the age difference in study participants. Our findings suggest the need for sexual education of adolescents to create awareness of precancerous cervical lesions.

A study done in Addis Ababa reported that having more than one sexual partners increase the likelihood of precancerous cervical lesion which is in line with our findings (15). This finding is supported by several studies done in Africa (16, 19, 26, 36). A meta-analysis of publications dealing with multiple sexual partners and cervical cancer revealed that having multiple sexual partners was significantly associated with the occurrence of cervical cancer(37). The reason for this could be sexual activity may increase the chance of transmission of HPV which is a causative agent for precancerous cervical lesion. The finding of our study underscores the importance of avoiding multiple sexual partners to prevent precancerous cervical lesions.

Our study showed that women having a husband or partner with two or more lifetime sexual partners had a higher odds of having a precancerous cervical cancer lesion. Our finding is similar with previous studies done in Ethiopia and Uganda which stated that multiple sexual behaviour of male partners increases the risk of precancerous cervical 
lesion $(15,24,38)$. Taken together these findings indicate that effort is needed to raise awareness of the women and their husbands/partners in relation to multiple sexual partners and the risk of precancerous cervical lesion.

The findings of our study should be interpreted in light of the following limitations. There may be misclassification of cases and controls since the study use current VIA result to classify the cases and controls. The study was facility-based and may not be representative of the larger group in the population. Moreover, there may be social desirability bias since the study assessed the life style and sexual behaviour of the participants.

\section{Conclusions}

This study revealed that women age 30-39 years old, monthly income less than 66USD, age at first sexual intercourse less than or equal to 20 years and a history of having multiple sexual partners were risk factors for precancerous cervical lesions. Strategies to prevent precancerous cervical lesions should focus on modification of life style and sexual behaviour. The findings of this study highlights the implications for policy makers by suggesting that targeting older women for cervical cancer screening, addressing inequalities and educating about risk sexual behaviour may reduce precancerous cervical lesions. Further longitudinal study is needed to identify the awareness of women in relation to cervical cancer screening.

\section{Declarations}

\section{Acknowledgments}

We would like to acknowledge Pharma College for funding this research project. We would also like to thank Stephen Hancock for providing language revision and proof reading of the manuscript.

\section{Author's contribution}

TT and MA conceived and designed the study. TT and MA developed the tools. TT, MA, HB, WS followed the data collection process. TT performed data anlaysis.TT wrote the first draft of the manuscript. TT, MA, HB, WS reviewed the manuscript. All authors read and approved the manuscript.

\section{Competing interests}

The authors declare that they have no competing interests

\section{Ethical statement}


The study was approved by the Research Ethics Committee of the Pharama College, Hawassa, Ethiopia.

\section{Funding sources}

Pharama College, Hawassa, Ethiopia has funded the research. The funder have no role in the design of the study, data collection, data processing and analysis and interpretation of the results of the study.

Data sharing Data essential for conclusion are included in this manuscript. Additional data can be obtained from the corresponding author on reasonable request.

\section{References}

1. Kjaer SK, Chackerian B, van den Brule AJ, Svare El, Paull G, Walbomers JM, et al. High-risk human papillomavirus is sexually transmitted: evidence from a follow-up study of virgins starting sexual activity (intercourse). Cancer epidemiology, biomarkers \& prevention : a publication of the American Association for Cancer Research, cosponsored by the American Society of Preventive Oncology. 2001;10(2):101-6.

2. Siracusano S, Silvestri T, Casotto D. Sexually transmitted diseases: epidemiological and clinical aspects in adults. Urologia. 2014;81(4):200-8.

3. Subramanya D, Grivas PD. HPV and cervical cancer: updates on an established relationship. Postgraduate medicine. 2008;120(4):7-13.

4. World Health Organization. Cervical cancer. WHO. 2018.

5. Ferlay J, Soerjomataram I, Dikshit R, Eser S, Mathers C, Rebelo M, et al. Cancer incidence and mortality worldwide: sources, methods and major patterns in GLOBOCAN 2012. International journal of cancer. 2015;136(5):E359-86.

6. De Vuyst H, Alemany L, Lacey C, Chibwesha CJ, Sahasrabuddhe V, Banura C, et al. The burden of human papillomavirus infections and related diseases in sub-saharan Africa. Vaccine. 2013;31 Suppl 5:F32-46.

7. Alliance for Cervical Cancer Prevention. New evidence on the impact of cervical cancer screening and treatment using HPV DNA tests, visual inspection, or cytology. Cervical Cancer Prevention Fact Sheet. 2009.

8. Bruni L, Albero G, Serrano B, Mena M, Gómez D, Muñoz J, et al. ICO/IARC Information Centre on HPV and Cancer (HPV Information Centre). Human Papillomavirus and Related Diseases in Ethiopia. Summary Report 17 June 2019. 2019.

9. Federal Democratic Republic of Ethiopia Ministry of Health. Health Sector Development Programme IV. 2010. 
10. Federal Democratic Republic of Ethiopia Ministry of Health. Guideline for Cervical Cancer Prevention and Control in Ethiopia. 2015.

11. Getachew S, Getachew E, Gizaw M, Ayele W, Addissie A, Kantelhardt EJ. Cervical cancer screening knowledge and barriers among women in Addis Ababa, Ethiopia. PloS one. 2019;14(5):e0216522.

12. Shiferaw S, Addissie A, Gizaw M, Hirpa S, Ayele W, Getachew S, et al. Knowledge about cervical cancer and barriers toward cervical cancer screening among HIV-positive women attending public health centers in Addis Ababa city, Ethiopia. Cancer medicine. 2018;7(3):903-12.

13. Nega AD, Woldetsadik MA, Gelagay AA. Low uptake of cervical cancer screening among HIV positive women in Gondar University referral hospital, Northwest Ethiopia: cross-sectional study design. BMC women's health. 2018;18(1):87.

14. Aweke YH, Ayanto SY, Ersado TL. Knowledge, attitude and practice for cervical cancer prevention and control among women of childbearing age in Hossana Town, Hadiya zone, Southern Ethiopia: Community-based cross-sectional study. PLoS One. 2017;12(7):e0181415.

15. Teame H, Addissie A, Ayele W, Hirpa S, Gebremariam A, Gebreheat G, et al. Factors associated with cervical precancerous lesions among women screened for cervical cancer in Addis Ababa, Ethiopia: A case control study. PLoS One. 2018;13(1):e0191506.

16. Kassa RT. Risk factors associated with precancerous cervical lesion among women screened at Marie Stops Ethiopia, Adama town, Ethiopia 2017: a case control study. BMC research notes. 2018;11(1):145.

17. Makuza JD, Nsanzimana S, Muhimpundu MA, Pace LE, Ntaganira J, Riedel DJ. Prevalence and risk factors for cervical cancer and pre-cancerous lesions in Rwanda. The Pan African medical journal. 2015;22:26.

18. Okunade KS, Nwogu CM, Oluwole AA, Anorlu RI. Prevalence and risk factors for genital high-risk human papillomavirus infection among women attending the out-patient clinics of a university teaching hospital in Lagos, Nigeria. The Pan African medical journal. 2017;28:227.

19. Gedefaw A, Astatkie A, Tessema GA. The prevalence of precancerous cervical cancer lesion among HIV-infected women in southern Ethiopia: a cross-sectional study. PLoS One. 2013;8(12):e84519.

20. Teame H, Gebremariam L, Kahsay T, Berhe K, Gebreheat G, Gebremariam G. Factors affecting utilization of cervical cancer screening services among women attending public hospitals in Tigray region, Ethiopia, 2018; Case control study. PloS one. 2019;14(3):e0213546.

21. Maldonado G, Greenland S. Simulation study of confounder-selection strategies. American journal of epidemiology. 1993;138(11): 923-36.

22. World Health Organization. Attaining the nine global non-communicable diseases targets; a shared responsibility. Global Status Report on non-communicable diseases. . Geneva: WHO. 2014.

23. The United Nations Inter-Agency Task Force The United Nations Inter-Agency Task Force on the Prevention and Control of Noncommunicable Diseases (UNIATF). 2016.

24. Bezabih M, Tessema F, Sengi H, Deribew A. Risk Factors Associated with Invasive Cervical Carcinoma among Women Attending Jimma University Specialized Hospital, Southwest Ethiopia: A 
Case Control Study. Ethiopian journal of health sciences. 2015;25(4):345-52.

25. Seppa K, Pitkaniemi J, Malila N, Hakama M. Age-related incidence of cervical cancer supports two aetiological components: a population-based register study. BJOG : an international journal of obstetrics and gynaecology. 2016;123(5):772-8.

26. Gessesse Z, Tadesse Z, Alemayehu M, Hiruye A, Getachew Y, Derbew M, et al. DETERMINANT FACTORS OF VISUAL INSPECTION WITH ACETIC ACID (VIA) POSITIVE LESIONS AMONG HIV POSITIVE WOMEN IN MEKELLE HOSPITAL, NORTHERN ETHIOPIA: A CASE CONTROL STUDY. Ethiopian medical journal. 2015;Suppl 2:17-24.

27. Jung HM, Lee JS, Lairson DR, Kim Y. The Effect of National Cancer Screening on Disparity Reduction in Cancer Stage at Diagnosis by Income Level. PloS one. 2015;10(8):e0136036.

28. Chidyaonga-Maseko F, Chirwa ML, Muula AS. Underutilization of cervical cancer prevention services in low and middle income countries: a review of contributing factors. The Pan African medical journal. 2015;21:231.

29. Compaore S, Ouedraogo CMR, Koanda S, Haynatzki G, Chamberlain RM, Soliman AS. Barriers to Cervical Cancer Screening in Burkina Faso: Needs for Patient and Professional Education. Journal of cancer education : the official journal of the American Association for Cancer Education. 2016;31(4):760-6.

30. Parikh S, Brennan P, Boffetta P. Meta-analysis of social inequality and the risk of cervical cancer. International journal of cancer. 2003;105(5):687-91.

31. Jiang Y, Hu SY, Hernandez Donoso L, Li X, Zheng MH, Zhao FH. A Systematic Literature Review on Risk Factors for Cervical Cancer in Chinese Population. Value in health : the journal of the International Society for Pharmacoeconomics and Outcomes Research. 2014;17(7):A733-4.

32. Lukac A, Sulovic N, Smiljic S, Ilic AN, Saban O. The Prevalence of the Most Important Risk Factors Associated with Cervical Cancer. Materia socio-medica. 2018;30(2):131-5.

33. Reis Nesrin, Beji NK, Kilic D. Risk Factors for Cervical Cancer: Results from a Hospital-Based CaseControl Study. International Journal of Hematology and Oncology. 2011;21(3).

34. Schiffman M, Wentzensen N, Wacholder S, Kinney W, Gage JC, Castle PE. Human papillomavirus testing in the prevention of cervical cancer. Journal of the National Cancer Institute. 2011;103(5):36883.

35. Elson DA, Riley RR, Lacey A, Thordarson G, Talamantes FJ, Arbeit JM. Sensitivity of the cervical transformation zone to estrogen-induced squamous carcinogenesis. Cancer research. 2000;60(5):1267-75.

36. Ononogbu U, Almujtaba M, Modibbo F, Lawal I, Offiong R, Olaniyan O, et al. Cervical cancer risk factors among HIV-infected Nigerian women. BMC public health. 2013;13:582.

37. Liu ZC, Liu WD, Liu YH, Ye XH, Chen SD. Multiple Sexual Partners as a Potential Independent Risk Factor for Cervical Cancer: a Meta-analysis of Epidemiological Studies. Asian Pacific journal of cancer prevention : APJCP. 2015;16(9):3893-900. 
38. Newton R, Ziegler J, Casabonne D, Beral V, Mbidde E, Carpenter L, et al. A case-control study of cancer of the uterine cervix in Uganda. European journal of cancer prevention : the official journal of the European Cancer Prevention Organisation (ECP). 2007;16(6):555-8.

\section{Tables}

Table 1 Socio-demographic characteristics of women screened for cervical cancer in south Ethiopia, 2018. 


\begin{tabular}{|c|c|c|}
\hline Variables & Case n (\%) & Control n (\%) \\
\hline \multicolumn{3}{|l|}{ Age(years) } \\
\hline $21-29$ & $13(13.3)$ & $62(31.5)$ \\
\hline $30-39$ & $66(67.3)$ & $118(59.9)$ \\
\hline $40-49$ & $19(19.4)$ & $17(8.6)$ \\
\hline \multicolumn{3}{|l|}{ Residence } \\
\hline Urban & $54(55.1)$ & $120(60.9)$ \\
\hline Rural & $44(44.9)$ & 77(39.1) \\
\hline \multicolumn{3}{|l|}{ Religion } \\
\hline Ethiopian Orthodox & $32(32.7)$ & $64(32.5)$ \\
\hline Muslim & $18(18.4)$ & $19(9.6)$ \\
\hline Protestant & $44(44.9)$ & $110(55.8)$ \\
\hline Catholic & $4(4.1)$ & $4(2.0)$ \\
\hline \multicolumn{3}{|l|}{ Marital status } \\
\hline Married & $90(91.8)$ & 178(90.4) \\
\hline Single & $1(1.0)$ & $7(3.6)$ \\
\hline Widowed & $5(5.1)$ & $5(2.5)$ \\
\hline Divorced or separated & $2(2.0)$ & $7(3.6)$ \\
\hline \multicolumn{3}{|l|}{ Women's educational level } \\
\hline Can't read and write & $17(17.3)$ & $31(15.7)$ \\
\hline Able to read and write but with no schooling & $15(15.3)$ & $23(11.7)$ \\
\hline Primary $1-4$ & 17(17.3) & $29(14.7)$ \\
\hline Primary 5-8 & $26(26.5)$ & $45(22.8)$ \\
\hline Secondary school & $10(10.2)$ & $34(17.3)$ \\
\hline College diploma and above & $13(13.3)$ & $35(17.8)$ \\
\hline \multicolumn{3}{|l|}{ Women's occupation } \\
\hline House wife & $33(33.7)$ & $65(33)$ \\
\hline Government employee & $14(14.3)$ & $35(17.8)$ \\
\hline Merchant & $26(26.5)$ & $40(20.3)$ \\
\hline Farmer & $11(11.2)$ & $29(14.7)$ \\
\hline Daily laborer & $5(5.1)$ & $10(5.1)$ \\
\hline Student & $6(6.1)$ & $9(4.6)$ \\
\hline Other & $3(3.1)$ & $9(4.6)$ \\
\hline \multicolumn{3}{|l|}{ Husband or partner educational status } \\
\hline Can't read and write & $9(9.3)$ & $12(6.3)$ \\
\hline Able to read and write but with no schooling & $11(11.3)$ & $15(7.9)$ \\
\hline Primary $1-4$ & $14(14.4)$ & $32(16.8)$ \\
\hline Primary 5-8 & $17(17.5)$ & $34(17.9)$ \\
\hline Secondary school & 19(19.6) & $38(20.0)$ \\
\hline College diploma and above & $27(27.8)$ & $59(31.1)$ \\
\hline \multicolumn{3}{|l|}{ Income per month(ETB) } \\
\hline$<=42$ USD & $39(39.8)$ & $48(24.4)$ \\
\hline 43-66 USD & $18(18.4)$ & $43(21.8)$ \\
\hline 67-139USD & $25(25.5)$ & $54(27.4)$ \\
\hline$>139$ USD & $16(16.3)$ & $52(26.4)$ \\
\hline
\end{tabular}

$1 \mathrm{USD}=28.48$

Table 2. Reproductive characteristics of women screened for cervical cancer in south Ethiopia, 2018. 


\begin{tabular}{|c|c|c|}
\hline Variables & Case n (\%) & Control n (\%) \\
\hline \multicolumn{3}{|l|}{ Parity } \\
\hline No & $4(4.1)$ & $6(3.0)$ \\
\hline $1-4$ & $59(60.2)$ & $179(90.9)$ \\
\hline$>=5$ & $35(35.7)$ & $12(6.1)$ \\
\hline \multicolumn{3}{|l|}{ Age of menarche } \\
\hline$<=12$ & $6(6.1)$ & $11(5.6)$ \\
\hline $13-15$ & $50(51.0)$ & $96(48.7)$ \\
\hline$>15$ & $42(42.9)$ & $90(45.7)$ \\
\hline \multicolumn{3}{|l|}{ Menstrual pattern } \\
\hline Regular & $67(68.4)$ & $142(72.1)$ \\
\hline Sometimes irregular & $20(20.4)$ & $43(21.8)$ \\
\hline Always irregular & 11(11.2) & $12(6.1)$ \\
\hline \multicolumn{3}{|c|}{ Currently using any form of contraceptive } \\
\hline Yes & $50(51.0)$ & 92(46.7) \\
\hline No & $48(49.0)$ & 105(53.3) \\
\hline \multicolumn{3}{|l|}{ Type of contraceptive } \\
\hline Oral contraceptive & $14(28.0)$ & $28(30.4)$ \\
\hline Injectable & $24(48.0)$ & $46(50.0)$ \\
\hline Implants & $9(18.0)$ & $13(14.1)$ \\
\hline IUCD & $3(6.0)$ & $5(5.4)$ \\
\hline \multicolumn{3}{|c|}{ Ever use of oral contraceptive } \\
\hline Yes & $58(59.2)$ & 101(51.3) \\
\hline No & $40(40.8)$ & $96(48.7)$ \\
\hline \multicolumn{3}{|l|}{ Birth interval } \\
\hline$<24$ months & $56(29.9)$ & $28(29.8)$ \\
\hline$>=24$ months & $66(70.2)$ & $131(70.1)$ \\
\hline \multicolumn{3}{|c|}{ History of recurrent abortion } \\
\hline Yes & $6(6.1)$ & $11(5.6)$ \\
\hline No & 92(93.9) & $186(94.4)$ \\
\hline \multicolumn{3}{|l|}{ Age at first pregnancy } \\
\hline$<=20$ & $52(53.1)$ & $96(48.7)$ \\
\hline$>20$ & $46(46.9)$ & $101(51.3)$ \\
\hline
\end{tabular}


Table 3: Lifestyle and sexual behaviour characteristics of women screened for cervical cancer in south Ethiopia, 2018.

\begin{tabular}{|c|c|c|}
\hline Variables & Case n (\%) & Control n (\%) \\
\hline \multicolumn{3}{|c|}{ Age at first sexual intercourse } \\
\hline$<=20$ & $14(14.3)$ & $48(24.4)$ \\
\hline$>20$ & $84(85.7)$ & $149(75.6)$ \\
\hline \multicolumn{3}{|c|}{ Life time number of sexual partner } \\
\hline One & $65(66.3)$ & 181 (91.9) \\
\hline Two or above & $33(33.7)$ & 16(8.1) \\
\hline \multicolumn{3}{|c|}{ Lifetime sexual partners of the husband } \\
\hline No or one & $62(63.3)$ & $160(81.2)$ \\
\hline Two or above & $36(36.7)$ & $37(18.8)$ \\
\hline \multicolumn{3}{|l|}{ History of STI } \\
\hline Yes & 28(28.6) & $23(11.7)$ \\
\hline No & $70(71.4)$ & $174(88.3)$ \\
\hline \multicolumn{3}{|c|}{ Partner history of STI } \\
\hline Yes & 17(17.3) & 17(8.6) \\
\hline No & $81(82.7)$ & $180(91.4)$ \\
\hline \multicolumn{3}{|c|}{ History of post-coital bleeding } \\
\hline Yes & 15(15.3) & $13(6.6)$ \\
\hline No & 83(84.7) & 184(93.4) \\
\hline \multicolumn{3}{|c|}{ Family history of cervical cancer } \\
\hline Yes & $10(10.2)$ & $10(5.1)$ \\
\hline No & 88(89.8) & $187(94.9)$ \\
\hline \multicolumn{3}{|c|}{ Previously screened for cervical cancer } \\
\hline Yes & $21(21.4)$ & 35(17.8) \\
\hline No & $77(78.6)$ & $162(82.2)$ \\
\hline \multicolumn{3}{|l|}{ HIV status } \\
\hline Reactive & 13(13.3) & 7(3.6) \\
\hline Non-reactive & 85(86.7) & $190(96.4)$ \\
\hline \multicolumn{3}{|c|}{ Ever history of smoking } \\
\hline Yes & $6(6.1)$ & $7(3.6)$ \\
\hline No & 92(93.9) & $190(96.4)$ \\
\hline \multicolumn{3}{|c|}{ History of chronic disease } \\
\hline Yes & $6(6.1)$ & $10(5.1)$ \\
\hline No & 92(93.9) & 187(94.9) \\
\hline \multicolumn{3}{|c|}{ Vulva washing after every sexual intercourse } \\
\hline Yes & 72(73.5) & 135(68.5) \\
\hline No & $26(26.5)$ & $62(31.5)$ \\
\hline
\end{tabular}


Table 4: A multivariate logistic regression on determinants of precancerous cervical lesion in south Ethiopia, 2018.

\begin{tabular}{|c|c|c|c|c|}
\hline Variables & Case n (\%) & Control n (\%) & COR (CI 95\%) & AOR (CI 95\%) \\
\hline \multicolumn{5}{|l|}{ Age(years) } \\
\hline $21-29$ & $13(13.3)$ & $62(31.5)$ & 1 & 1 \\
\hline $30-39$ & $66(67.3)$ & 118(59.9) & $2.67(1.37-5.21)$ & $2.51(1.03-6.08) *$ \\
\hline $40-49$ & $19(19.4)$ & $17(8.6)$ & $5.33(2.20-12.93)$ & $1.92(0.57-6.50)$ \\
\hline \multicolumn{5}{|l|}{ Parity } \\
\hline No & $4(4.1)$ & $6(3.0)$ & & 1 \\
\hline $1-4$ & $59(60.2)$ & $179(90.9)$ & $0.49(0.14-1.81)$ & $0.16(0.28-1.01)$ \\
\hline$>=5$ & $35(35.7)$ & $12(6.1)$ & $4.38(1.05-18.19)$ & $1.61(0.23-11.48)$ \\
\hline \multicolumn{5}{|c|}{ Income per month } \\
\hline$<=42$ USD & $39(39.8)$ & $48(24.4)$ & $2.64(1.37-5.21)$ & $3.41(1.34-8.70)$ \\
\hline 43-66 USD & $18(18.4)$ & $43(21.8)$ & $1.36(0.62-2.98)$ & $3.63(1.31-9.88) *$ \\
\hline 67-139 USD & $25(25.5)$ & $54(27.4)$ & $1.51(0.72-3.14)$ & $2.03(0.79-5.25)$ \\
\hline >139 USD & 16(16.3) & $52(26.4)$ & 1 & 1 \\
\hline \multicolumn{5}{|c|}{ Age at first sexual intercourse (years) } \\
\hline$<=20$ & $14(14.3)$ & $48(24.4)$ & $1.93(1.01-3.71)$ & $2.39(1.14-5.47) *$ \\
\hline$>20$ & 84(85.7) & $149(75.6)$ & 1 & 1 \\
\hline \multicolumn{5}{|c|}{ Lifetime sexual partners } \\
\hline No or one & $65(66.3)$ & $181(91.9)$ & 1 & 1 \\
\hline Two or above & 33(33.7) & $16(8.1)$ & $5.74(2.97-11.12)$ & $4.70(2.02-10.95)^{*}$ \\
\hline \multicolumn{5}{|c|}{ Number of sexual partner of the husband } \\
\hline No or one & 62(63.3) & $160(81.2)$ & & 1 \\
\hline Two or above & $36(36.7)$ & $37(18.8)$ & $2.51(1.46-4.33)$ & $2.98(1.35-6.65) *$ \\
\hline \multicolumn{5}{|l|}{ History of STI } \\
\hline Yes & 28(28.6) & $23(11.7)$ & $3.03(1.63-5.61)$ & 2.15(0.57--8.05) \\
\hline No & $70(71.4)$ & $174(88.3)$ & 1 & 1 \\
\hline \multicolumn{5}{|c|}{ Ever history of STD in sexual partner } \\
\hline Yes & 17(17.3) & $17(8.6)$ & $2.22(1.08-4.57)$ & $1.47(0.33-6.56)$ \\
\hline No & 81(82.7) & 180(91.4) & 1 & \\
\hline \multicolumn{5}{|c|}{ Ever Use of oral contraception } \\
\hline Yes & $58(59.2)$ & 101(51.3) & $1.38(0.84-2.25)$ & 1.07(0.57-1.99) \\
\hline No & $40(40.8)$ & 96(48.7) & 1 & 1 \\
\hline \multicolumn{5}{|c|}{ Family history of cervical cancer } \\
\hline Yes & $10(10.2)$ & $10(5.1)$ & $2.12(0.85-5.29)$ & $2.29(0.73-7.20)$ \\
\hline No & 88(89.8) & 187(94.9) & 1 & 1 \\
\hline \multicolumn{5}{|c|}{ History of post-coital bleeding } \\
\hline Yes & 15(15.3) & $13(6.6)$ & $2.56(1.17-5.62)$ & $1.89(0.67-5.35)$ \\
\hline No & $83(84.7)$ & $184(93.4)$ & 1 & 1 \\
\hline \multicolumn{5}{|l|}{ HIV status } \\
\hline Reactive & 13(13.3) & $7(3.6)$ & $4.15(1.60-10.78)$ & $3.32(0.96-10.90)$ \\
\hline Non-reactive & $85(86.7)$ & $190(96.4)$ & 1 & 1 \\
\hline
\end{tabular}


Page 17/17 